\title{
Design of a Solar Absorption Cooling System: Case Study
}

\author{
Peter Jenkins' ${ }^{1}$, Monaem Elmnifi ${ }^{2}$, Abdalfadel Younis ${ }^{3}$, Alzaroog Emhamed ${ }^{4}$, Moneer Alshilmany ${ }^{5}$ \\ ${ }^{1}$ Department of Mechanical Engineering, University of Colorado, Denver, USA \\ ${ }^{2}$ Department of Mechanical Engineering, Bright Star University, Ajdabiya, Libya \\ ${ }^{3}$ Department of Mechanical Engineering, University of Omar Al-Mukhtar, Al-Bayda, Libya \\ ${ }^{4}$ Department of Electrical Engineering, Bright Star University, Ajdabiya, Libya \\ ${ }^{5}$ General Electric Company, Al-Marj, Libya \\ Email: Peter.jenkins@ucdenver.edu,Monm.hamad@yahoo.co.uk, Abdalfadel.younis@omu.edu.ly
}

How to cite this paper: Jenkins, P., Elmnifi, M., Younis, A., Emhamed, A. and Alshilmany, M. (2020) Design of a Solar Absorption Cooling System: Case Study. Journal of Power and Energy Engineering, 8, 1-15.

https://doi.org/10.4236/jpee.2020.81001

Received: November 12, 2019

Accepted: January 4, 2020

Published: January 7, 2020

Copyright $\odot 2020$ by author(s) and Scientific Research Publishing Inc. This work is licensed under the Creative Commons Attribution International License (CC BY 4.0).

http://creativecommons.org/licenses/by/4.0/

\begin{abstract}
In this paper, the principles of the operation of an adsorption cooling circuit and its operating points are analyzed through both a thermodynamic analysis and with mathematical calculations of the whole circuit and using EES to design the solar system. The results of the program are discussed and highlighted by comparing them with the results of the theoretical and experimental studies in the references.
\end{abstract}

\section{Keywords}

Renewable Energy, Solar Radiation, Adsorption, Cooling System, Libya

\section{Introduction}

Research on renewable energies is one of the most important issues of our present time, especially solar energy, as a clean energy and as an alternative solution to the polluting and depleting fossil energy. In addition, solar is considered available in the countries that have abundant solar radiation [1]. Since the beginning of his time, man has sought to seek comfort and to provide the best conditions for ideal living. Cooling and air-conditioning have become basic requirements of his daily life.

It was noted from the global statistics that researchers estimated in 2005 that there was a clear rise in the demand for the use of refrigeration and air conditioning. $25 \%$ of the energy used in the world was used for air conditioning and cooling [2]. Libya lies in the center of North Africa between latitudes $20^{\circ} \mathrm{N}$ $33^{\circ} \mathrm{N}$ and longitude $10^{\circ} \mathrm{E}-25^{\circ} \mathrm{E}$. The country is located in the Sun Earth belt. 
According to the report of the Institute of Thermodynamics Engineering at the German Space Center in Stuttgart [1], the direct natural solar radiation varies from $1900 \mathrm{kWh} / \mathrm{m}^{2}$ a year in the far north of the country to more than 2800 $\mathrm{kWh} / \mathrm{m}^{2}$ a year in parts of the south-east.

Concentrated solar power plants can be considered economically valuable only for sites with direct solar radiation above $1800 \mathrm{kWh} / \mathrm{m}^{2}$ a year [3]. All Libyan lands can meet this condition with higher potential than the southern parts of the country. The sector of buildings is, on a global scale, one of the largest energy consumers (together with transport and industry sectors). Over time solutions were developed to meet the needs of users. One solution was the widespread use of air conditioning systems based on electric driven compression technology, which have greatly improved the quality of indoor environments in buildings. However, these systems have high-energy consumption in heating and cooling. The costs associated with air conditioning have been increasing and it's expected that this growth will be even more pronounced in coming years, either due to the rising standards in comfort required by the occupants, or due to climate changes [3] [4].

Today in Libya, buildings account for about $60 \%$ of the electric energy consumption and about $30 \%$ of primary energy consumption [5], this makes this sector a target for the improvement of energy efficiency ratings. Thus, any measure to keep or improve standards in indoor comfort, and at the same time allowing for the reduction in the energy bill, should be an aim of research. This paper proposes to analyze the use of a solar-based system to obtain the required thermal energy for heating and cooling, as well as the production of domestic hot water (DHW).

The idea for this research was developed after reviewing what was available in this field of scientific experiments and research. Many references were studied of solar-powered cooling applications; among these experimental studies was the design of a solar powered refrigerator adsorption system in China that could absorb about $18 \mathrm{MJ} / \mathrm{m}^{2}$ of solar radiation [6]. Using this research, we were able to design a cooling system based on the principles of adsorption and work on modeling the system variables and their impact on performance of the cooling system.

\section{System and Process Description}

Intermittent adsorption systems usually have a single bed adsorption cycle that has been improved for some applications, such as preservation of food and vaccine storage. The adsorption system consists of three main parts: a solar collector with adsorbent bed, where a porous solid material is placed, a condenser, and an evaporator, as shown in Figure 1. The operating cycle of the system has four processes. In Figure 1, line (1-2) represents the heating process and line (2-3) represents the desorbing process. The cooling process is represented by line (3-4) with the desorbing process represented by line (4-1). During the heating 

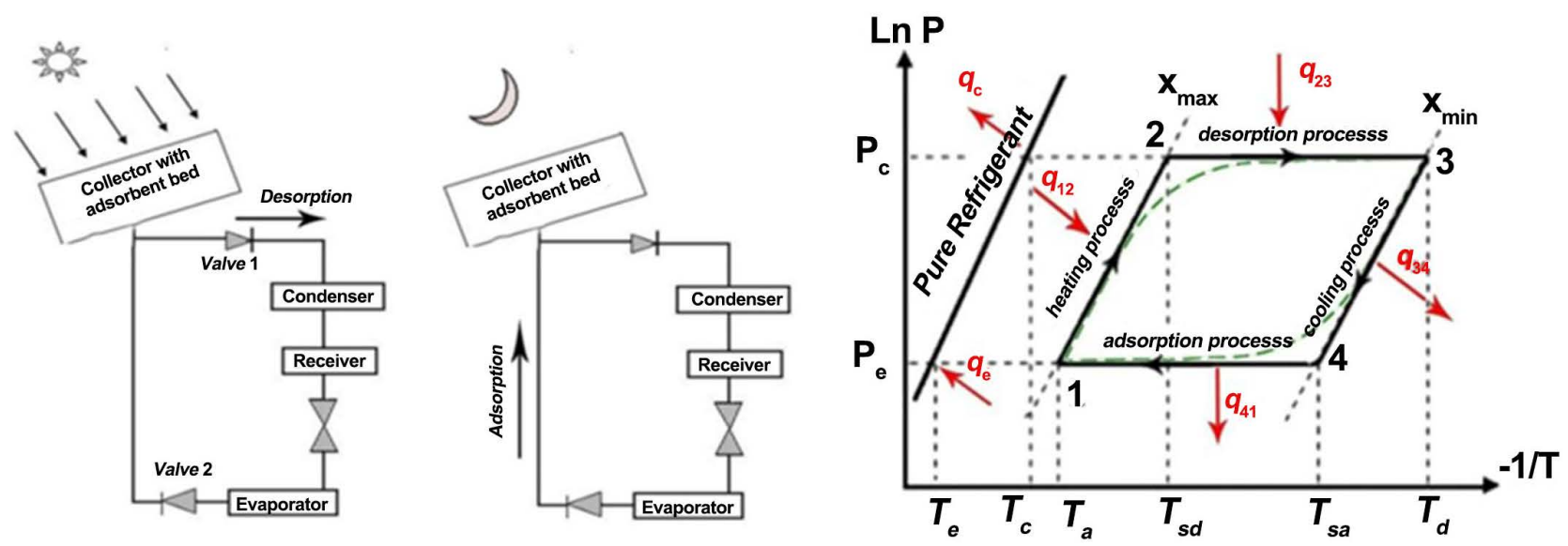

Figure 1. Schematic of the solar adsorption cooling system.

period, the adsorbent bed receives heat from the solar energy that raises the temperature of the pair of adsorbent and adsorbate, as shown in Figure 1, line $1-2$, which is an isosteric heating process at constant concentration of the adsorbate, $x_{\max }$. When the adsorbent bed pressure reaches the pressure of the condenser, the adsorbate vapor diffuses from the collector and is collected and condensed in the condenser (line 2-3, desorption process at condenser pressure) so that the concentration of the adsorbate in the reactor reaches the minimum value $\left(\mathrm{x}_{\min }\right)$ at the end of this desorption process. This process is followed by cooling the generator (line 3-4, isosteric cooling process). Then, the liquid adsorbate flows from the condenser to the evaporator. After that, the adsorbent adsorbs the refrigerant that comes from the evaporator (line 4-1, adsorption process at evaporator pressure). As a result, the liquid water in evaporator is converted into ice [7].

\section{Adsorption Chiller}

The adsorption system in Figure 2 can be compared to a conventional air conditioner or refrigerator with a thermally driven adsorption compressor. The ability to be driven by heat used for desorption, instead of an electric powered compressor, makes adsorption cycles attractive for electrical energy savers. Also, since fixed adsorbent beds are usually employed, these cycles can be operational without moving parts other than magnetic valves; this results in low vibration system with high reliability, and very long life. The uses of fixed beds also result in intermittent cycle operation, with adsorbent beds changing between adsorption and desorption stages [8] [9].

\section{Case Study}

For this study, one of Al-Marj University's buildings was selected. The building was composed by two floors with a total surface area of $1450 \mathrm{~m}^{2}$. The building did not have any conditioning systems. The building was conditioned using electrical power. Due to the non-existence of a conditioning system, it was 


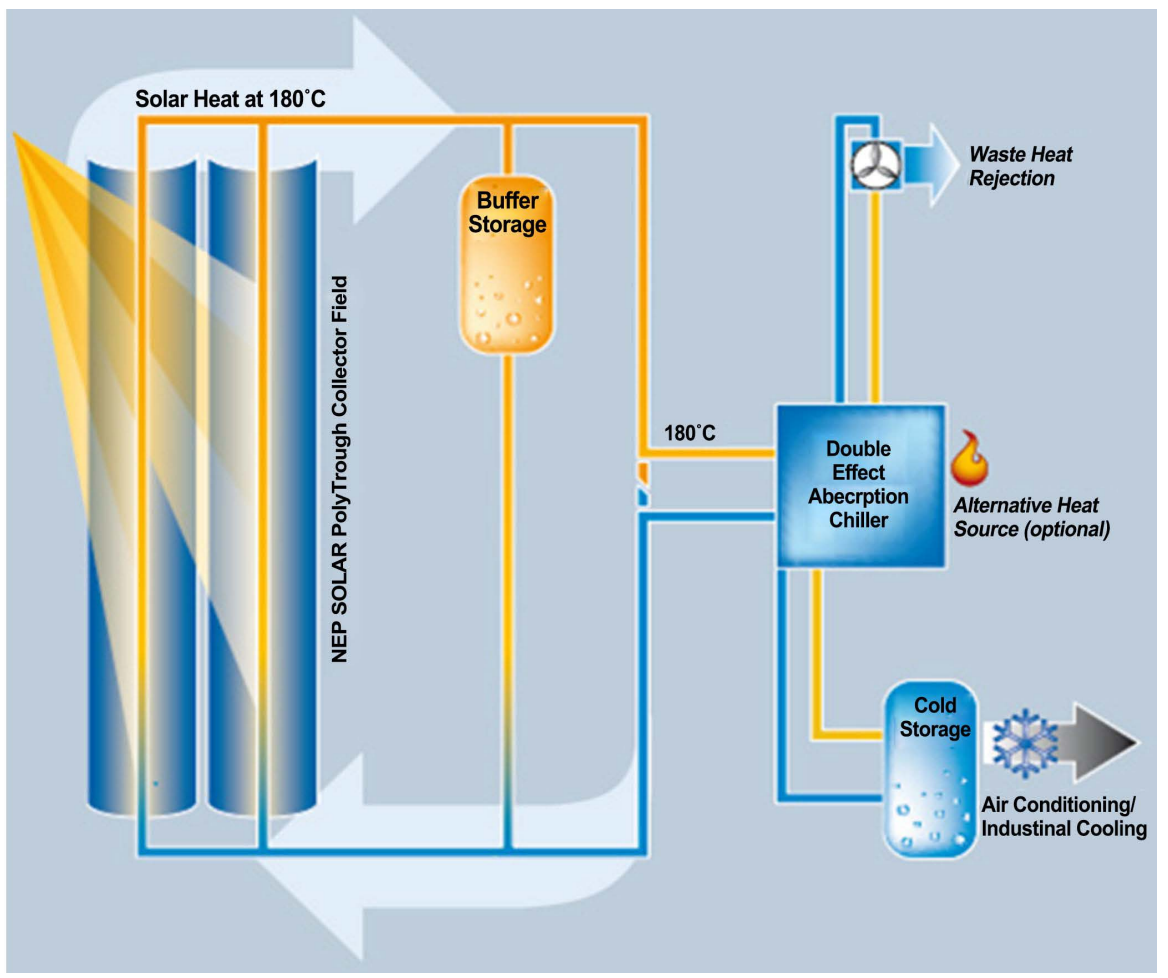

Figure 2. Energy scheme of an absorption solar cooling system.

considered that the cooling of the building was achieved by using an electrical compression chiller. Table 1 lists the heating and cooling periods considered for this study. The image of the building with solar thermal collectors is presented in Figure 3.

\section{Methodology}

To supply the energy for air conditioning system thermal energy was supplied by a parabolic trough solar collectors (PTC). The system was combined with an adsorption system (for cold air production). Thus, several approaches were evaluated for sizing of the system. These approaches took into account the energy required to meet the energy needs of the building, considering monthly average area of collectors, average area of collectors in the period of heating, average area of collectors in the period of cooling, and the month in which greater area of collectors was needed. Another aspect to consider was that the installed collector power was equal to the power needed to satisfy the energy demand of the building. It was expected that total energy needs are not always satisfied due to the fluctuation of the availability of solar energy during the day.

\subsection{Solar Radiation}

The solar radiation parameters for Al-Marj city that were used for this study are presented in Table 2. These values were obtained from the Atmospheric Science Data Center maintained by NASA [10]. 
Table 1. Heating and cooling periods.

\begin{tabular}{cl}
\hline From November to March & Heating \\
From April to October & Cooling \\
\hline
\end{tabular}

Table 2. Solar parameters.

\begin{tabular}{ccc}
\hline Month & Insulation & Direct Normal Radiation \\
\cline { 2 - 3 } Jan & {$[$ hours $]$} & {$\left[\mathrm{kWh} / \mathrm{m}^{2}\right]$} \\
Feb & 10 & 3.21 \\
Mar & 11 & 4.18 \\
Apr & 12 & 5.39 \\
May & 13 & 6.48 \\
Jun & 14 & 7.06 \\
Jul & 15 & 7.65 \\
Aug & 15 & 7.79 \\
Sep & 14 & 7.20 \\
Oct & 12 & 6.06 \\
Nov & 11 & 4.82 \\
Dec & 10 & 3.57 \\
\hline
\end{tabular}
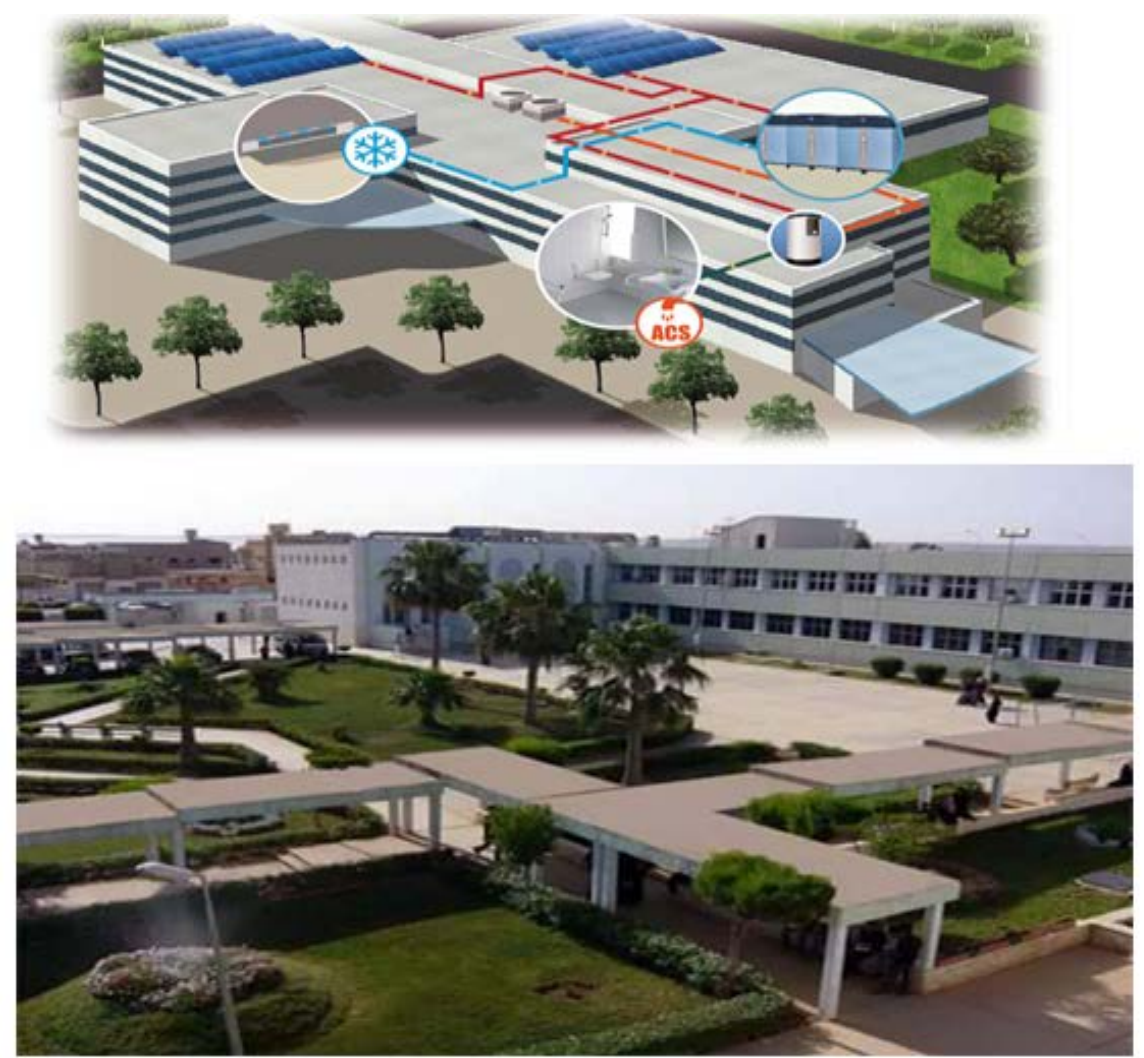

Figure 3. Administration building of Al-Marj University with solar thermal collectors. 


\subsection{Energy Needs of the Building}

The heating and cooling needs, presented in Table 3, were determined by using equations for calculating both cooling and heating loads.

\subsection{Design the Model}

Table 4 shows the design of the solar system that was needed to meet the energy demands of the building.

This design required 1200 NepSolar Poly Trough solar modules with a surface area of $140 \mathrm{~m}^{2}$ that delivered $77 \mathrm{~kW}$ of installed power. An SorTec adsorption chiller was considered for providing the cold production of $48 \mathrm{~kW}$.

\section{Mathematical Model}

In this section, a theoretical study evaluated the principles of the cooling circuit with absorption and its importance, compared to other cooling circuits using solar energy, in addition to the stages of its work with the working pairs. The basic adsorption refrigeration cycle can be presented by two methods: ideal cycle (solid lines) and actual cycle (dashed lines), as shown in Figure 1. The ideal cycle consists of two isosteric and two isobaric processes. The primary evaluations of the COP and the cooling effect are analyzed by the ideal cycle. For more accurate results, the actual cycle was used in the analyses of the system and the study of the effect of the various parameters. The system dead volume and heat transfer characteristics for each component were needed for the determination of the paths of actual cycle. Then, modeling this systemwas done on the computer using the Engineering Equations Solver (EES)with the sequence of the following steps [11].

\subsection{Thermodynamic Analysis of Solar Adsorption Cooling System}

This study was the basis that was used in the computer program for the determination of the equations needed to design the model system according to the fallowing order:

\subsection{Thermal Analysis of the Adsorption System}

The amount of heat added and was determined within the stages of the adsorption process evaluated according to the thermal equations, depending on the A-B-D-F circuit points shown on Figure 1. [12] [13] [14]:

$$
Q_{A B}=\dot{M}\left(C_{P, n t}+X \cdot C_{P, a t}\right)\left(T_{B}-T_{A}\right)
$$

$Q_{A B}$-The amount of added heat during the thermostatic heating phase (concentration stability) $(\mathrm{kJ} / \mathrm{h})$.

$\dot{M}$-The mass flow of the working pair across the container.

$C_{P, a t}, C_{P, n t}$-Specific thermal capacity of both adsorption and absorbent (kJ/ $\mathrm{kg} \cdot \mathrm{K})$.

$X$-Concentration of the substance absorbed by the adsorption. 
Table 3. Energy needs.

\begin{tabular}{cccc}
\hline Month & Heating & Cooling & Total \\
\hline Jan & {$[\mathrm{kWh}]$} & {$[\mathrm{kWh}]$} & {$[\mathrm{kWh}]$} \\
\hline Feb & 27.300 & 0 & 27.300 \\
Mar & 6.0001 & 0 & 6.0001 \\
Apr & 8.000 & 0 & 8.000 \\
May & 0 & 10.240 & 10.240 \\
Jun & 0 & 24.194 & 24.194 \\
Jul & 0 & 27.628 & 27.628 \\
Aug & 0 & 31.104 & 31.104 \\
Sep & 0 & 33.990 & 33.990 \\
Oct & 0 & 32.760 & 32.760 \\
Nov & 0 & 28.220 & 28.220 \\
Dec & 12.000 & 0 & 12.000 \\
Total & 23.400 & 0 & 23.400 \\
& 86.700 & 188.136 & 274.836
\end{tabular}

Table 4. Design details.

Technical data for the base module

\begin{tabular}{cc}
\hline Area $\left(\mathrm{m}^{2}\right)$ & 140 \\
Width $(\mathrm{m})$ & 1.2 \\
Length $(\mathrm{m})$ & 25 \\
Height $(\mathrm{m})$ & 1.63 \\
Focal length $(\mathrm{m})$ & 0.65 \\
Rim angle & $50^{\circ}$ \\
Weight $\left(\mathrm{kg} / \mathrm{m}^{2}\right)$ & 730 \\
\hline
\end{tabular}

$T_{B}-T_{A}-$ Temperature for two points $(A, B)(K)$.

$$
Q_{A D}=\dot{M}\left(C_{P, n t}+X \cdot C_{P, a t}\right)\left(T_{B}-T_{A}\right)+m \cdot \Delta H_{a}\left(X_{B}-X_{D}\right)
$$

Quantity of added heat during the process of generation $(\mathrm{kJ} / \mathrm{h}) Q_{A D}$.

The heat of adsorption is a latent heat for adsorption and evaporation $(\mathrm{kJ} / \mathrm{kg})$ $\Delta H_{a}$

$$
Q_{D F}=\dot{M}\left(C_{P, n t}+X \cdot C_{P, a t}\right)\left(T_{D}-T_{F}\right)
$$

Amount of heat during cooling process $(\mathrm{kJ} / \mathrm{h}) Q_{D F}$.

\subsection{Thermal Analysis of Condenser and Evaporator}

\subsubsection{Amount of Heat in the Condenser}

The amount of heat that the cooling medium put into the condenser was cooled and condensed into liquid in one of two ratios: 


$$
Q_{\text {con }}=m \cdot \Delta X \cdot h_{f g} \text { or } m \cdot \Delta X \cdot \Delta H
$$

$\Delta X$ - The difference between the maximum and micro concentrations within the cycle.

$\Delta H$ - The amount of evaporation temperature was given in tables or taken from the program used by the type of medium $(\mathrm{kJ} / \mathrm{kg})$.

$h_{f g}$-Enthalpy evaporation is also given by the type of medium employed in the cycle.

\subsubsection{Amount of Heat Absorbed in the Evaporator}

The amount of heat required to evaporate the cooling medium within the evaporator, where $Q_{e v a}$ was the convection of the place to be cooled, was known in advance according to the relationship:

$$
Q_{\text {eva }}=m \cdot \Delta X \cdot \Delta H_{v}+m \cdot \Delta X \cdot C_{p . a t .}\left(T_{c}-T_{E}\right) \text { or } m \cdot \Delta X \cdot h f_{\text {g.eva }}
$$

$T_{E}$-Evaporating temperature. $T_{c}$-Condensation temperature.

\subsection{Mass Transmission Equations}

The system used three blocks for mass transmission: the mass of the adsorption receptor (which is often neglected when the vessel was well designed), the mass of adsorption $\left(m_{n t}\right)$ and the mass of the absorbent $\left(m_{a t}\right)$ substance are formed by the working pair.

$$
m_{a t}=m_{n t} \cdot X_{\max } \text { or } \frac{Q_{\text {eva }}}{h_{o}-h_{i}}
$$

$h_{o}-h_{i}$-Enthalpy values on evaporator input and output.

\subsection{Performance Analysis of the Cooling System by Absorption}

The COP represents the ratio of the amount of heat needed to evaporate the cooling medium in the evaporator to the amount of heat provided to heat and generate the medium in the generator or the adsorption vessel according to the relationship in Equation (7).

$$
C O P=\frac{Q_{\text {eva }}}{Q_{g}}
$$

$Q_{g}$-The quantity of heat provided to the adsorption receptor was given by:

$$
Q_{g}=Q_{A B}+Q_{B D}
$$

\subsection{Thermal Analysis of the Solar System}

\subsubsection{Amount of Heat Required from the Solar System}

The thermal capacity required to cover the load of the adsorption vessel from the solar system was

$$
Q_{S}=\frac{Q_{g}}{\eta_{\text {con }} \cdot \eta_{\text {coll }}}
$$

$$
\eta_{\text {coll }} \text {-Solar Collector. } \eta_{\text {con. }} \text {-Connecting pipes. }
$$




\subsubsection{Required Area of Solar Collectors}

The area of the collector was determined from Equation (10) by the amount of heat required from the solar system and the value of the intensity of the solar radiation $(G)$.

$$
A_{\text {coll }, s}=\frac{Q_{S}}{G}
$$

From Equation (11), the number of solar collectors ( $n)$ was determined as,

$$
n=\frac{A_{\text {coll }}}{L x W}
$$

$L X W$-Length and width of solar collector.

\subsubsection{Performance Coefficient of the Solar System}

The coefficient of solar performance was the ratio between the amount of heat required to meet the required cooling load and the amount of heat produced from the solar system.

$$
C O P_{s n}=\frac{Q_{e v a}}{Q_{S}}
$$

\section{Results and Discussion}

Basic data used:

Working fluid used: lithium bromide/water (standard air conditioning).

The intensity of solar radiation $G=6000 \mathrm{Wh} / \mathrm{m}^{2} /$ day,

Ambient temperature $T_{a m b}=28^{\circ} \mathrm{C}$,

Evaporation temperature, $T_{\text {eva }}=15^{\circ} \mathrm{C}$,

Condensation temperature $\mathrm{T}_{\text {con }}=\left(T_{\text {amb }}+5\right)^{\circ} \mathrm{C}$,

Adsorption temperature $T_{A}=\left(T_{a m b}-3\right)$,

Generation temperature $T_{g}=90^{\circ} \mathrm{C}$, Entry temperature $T_{i n}=35^{\circ} \mathrm{C}$.

Type of collector: Parabolic trough with a highest temperature of $150^{\circ} \mathrm{C}$.

Enthalpy steam and absorption were calculated using the steam tables. After determining the basic data, the following results were reached.

\subsection{Absorption Cooling Cycle}

The cooling circuit was represented by adsorption after knowing the four points of pressure and temperature, and was obtained on more than one equivalent curve for these evaluations by changing their assigned values calculated within the program, as shown in Figure 4, in terms of pressure and temperature. Three cases were taken to change the data in each case; the degree of condensation and cooling with the degree of generation of generation and absorption, as shown in the Table 5.

\subsection{Effect of Condensation Temperature}

The cooling temperature of the cooling medium used to condense the vapor of the substance played a major role in determining the conditions of the system. 


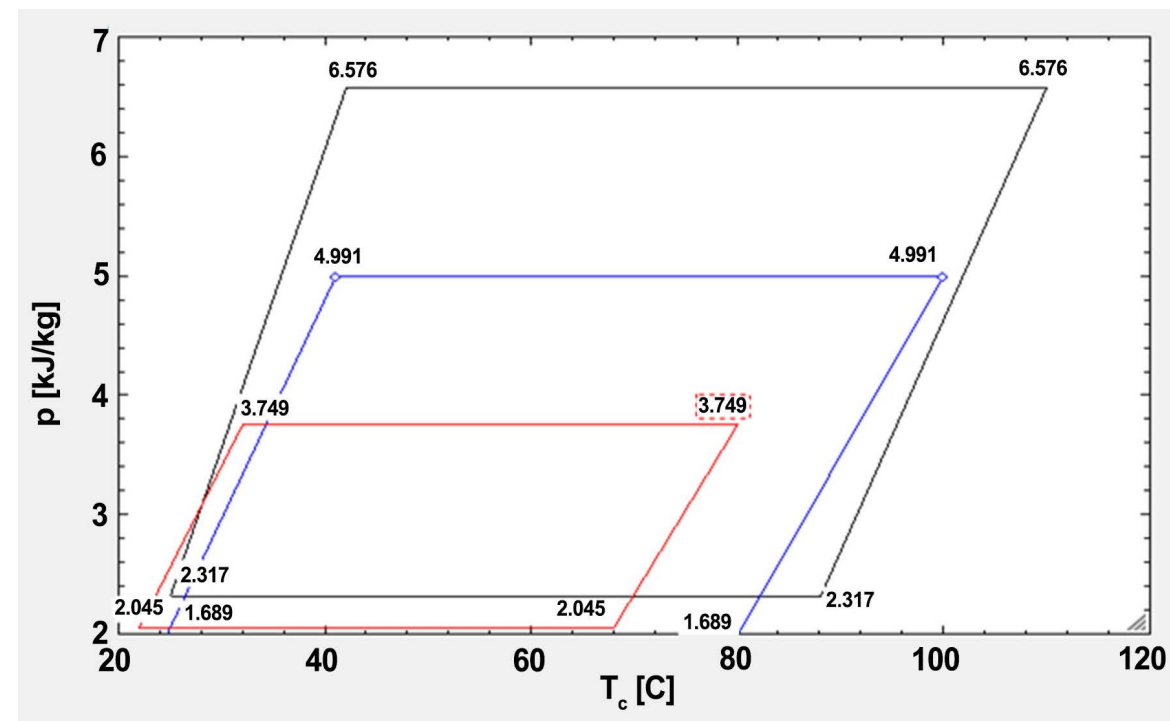

Figure 4. Three adsorbent circuits using the program.

Table 5. Data of the absorption cooling cycle in EES.

\begin{tabular}{ccccccccc}
\hline $\begin{array}{c}\text { Cycle } \\
{[1]}\end{array}$ & $\begin{array}{c}\text { Pressure } \\
{[\mathrm{KJ} / \mathrm{kg}]}\end{array}$ & $\begin{array}{c}\text { Temperature } \\
{\left[{ }^{\circ} \mathrm{C}\right]}\end{array}$ & $\begin{array}{c}\text { Cycle } \\
{[2]}\end{array}$ & $\begin{array}{c}\text { Pressure } \\
{[\mathrm{KJ} / \mathrm{kg}]}\end{array}$ & $\begin{array}{c}\text { Temperature } \\
{\left[{ }^{\circ} \mathrm{C}\right]}\end{array}$ & $\begin{array}{c}\text { Cycle } \\
{[3]}\end{array}$ & $\begin{array}{c}\text { Pressure } \\
{[\mathrm{KJ} / \mathrm{kg}]}\end{array}$ & $\begin{array}{c}\text { Temperature } \\
{\left[{ }^{\circ} \mathrm{C}\right]}\end{array}$ \\
\hline Run 1 & 2.045 & 22 & Run 1 & 1.689 & 23 & Run 1 & 2.317 & 25 \\
Run 2 & 3.749 & 32 & Run 2 & 4.991 & 41 & Run 2 & 6.578 & 42 \\
Run 3 & 3.749 & 80 & Run 3 & 4.991 & 100 & Run 3 & 6.576 & 110 \\
Run 4 & 2.045 & 68 & Run 4 & 1.689 & 78 & Run 4 & 2.317 & 88 \\
Run 5 & 2.045 & 22 & Run 5 & 1.689 & 23 & Run 5 & 2.317 & 25 \\
\hline
\end{tabular}

The effect of the condensation temperature on both the thermal performance coefficient and the specific cooling capacity was studied using four variable values of the evaporating temperature of the generation and absorption temperatures, as shown in Figure 5. It was determined that with the increase of the temperature of the condensation, both the performance coefficient and the qualitative capacity decrease. The objective of decreasing the performance factor was to reach the required generating temperature $\left(T_{g}\right)$, performance coefficient COP $=0.5$ at a temperature of condensation $T_{\text {con }}=33^{\circ} \mathrm{C}$.

\subsection{Effect of Evaporation Temperature}

This study showed that as the evaporation temperature decreased, the performance factor of the cycle decreases, as shown in Figure 6. This means that the required amount of heat will increase in order to reach a constant generating temperature and, consequently, required a larger system size.

\subsection{Effect of Concentration Ratios (x)}

The decrease in the concentration ratio resulted in a shift of the curve to the right. Therefore, it was noted that the coefficient of performance decreased when 


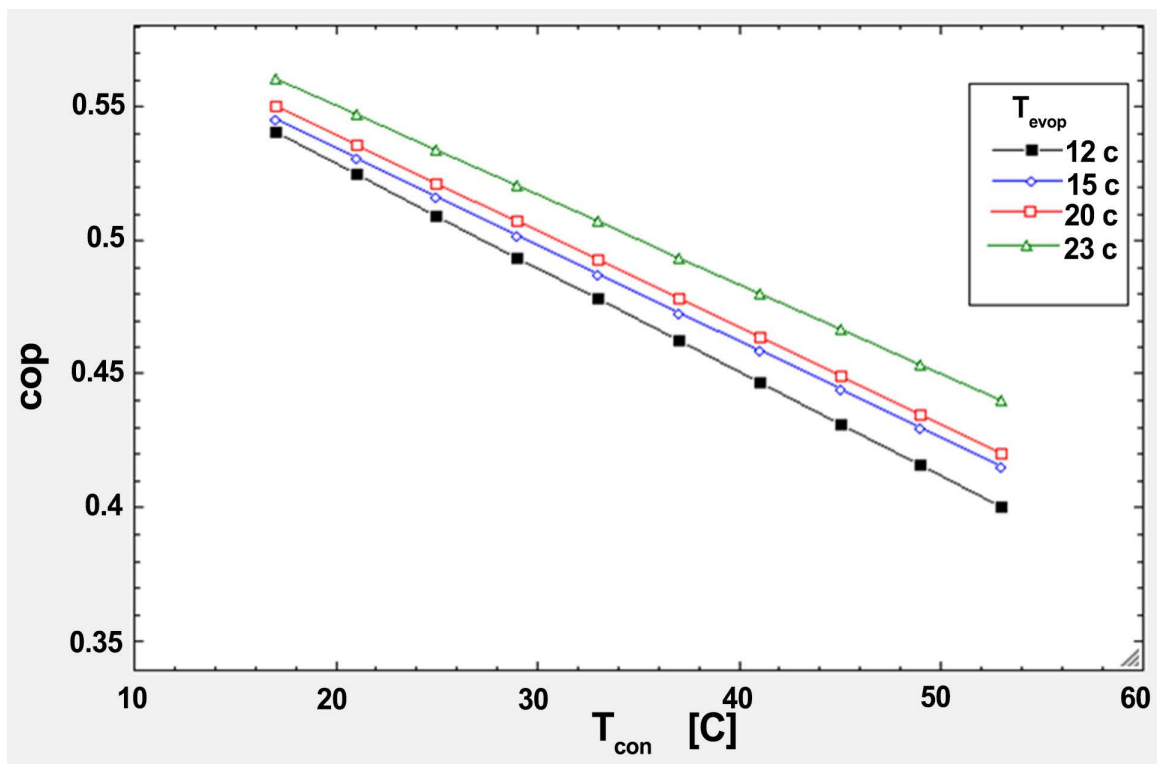

Figure 5. The effect of the degree of condensation on the coefficient of thermal performance at several values of evaporation temperature.

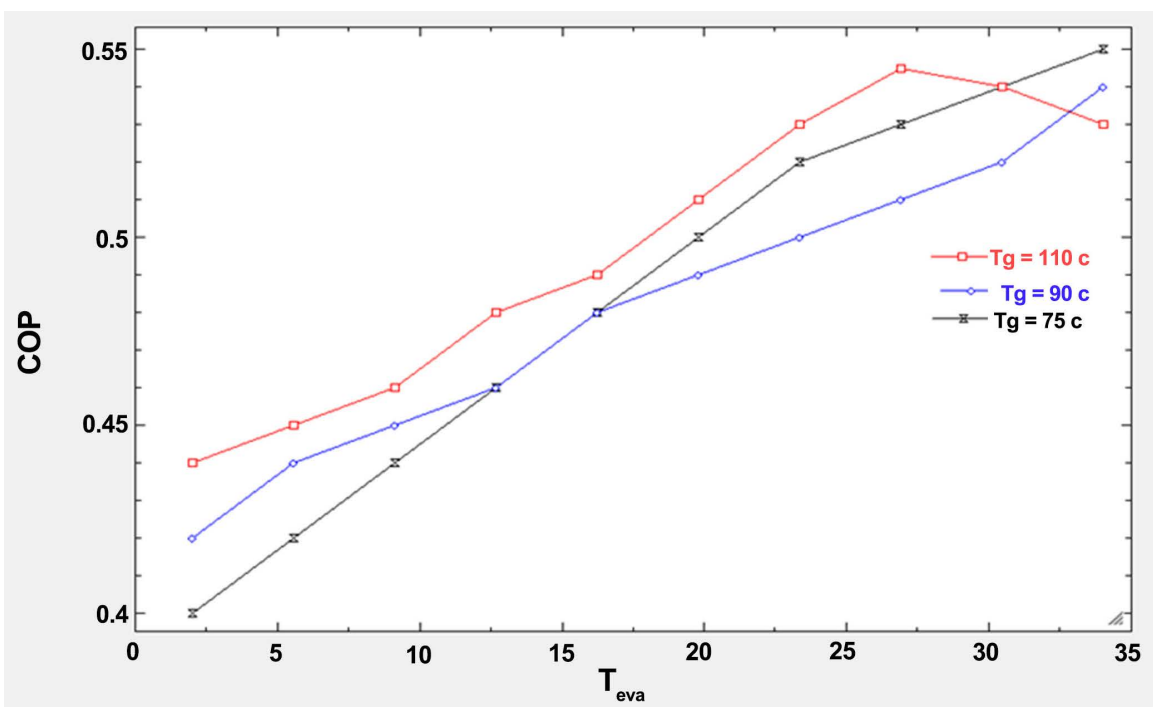

Figure 6. Effect of evaporation temperature on the performance coefficient at several values of the generation temperature.

this concentration ratio increased as shown in Figure 7. This means that there was a need for an increased amount of heat for the system to perform the generation process.

\subsection{Effect of Both Condensation Pressure and Evaporation on System Performance}

The values of vaporization and condensation pressure play an important role in determining the effectiveness of the adsorbed circuits. It was found that an improvement occurred with a decreasing pressure of the condenser, which resulted in an increase in the productivity, as shown in Figure 8. Condensation 


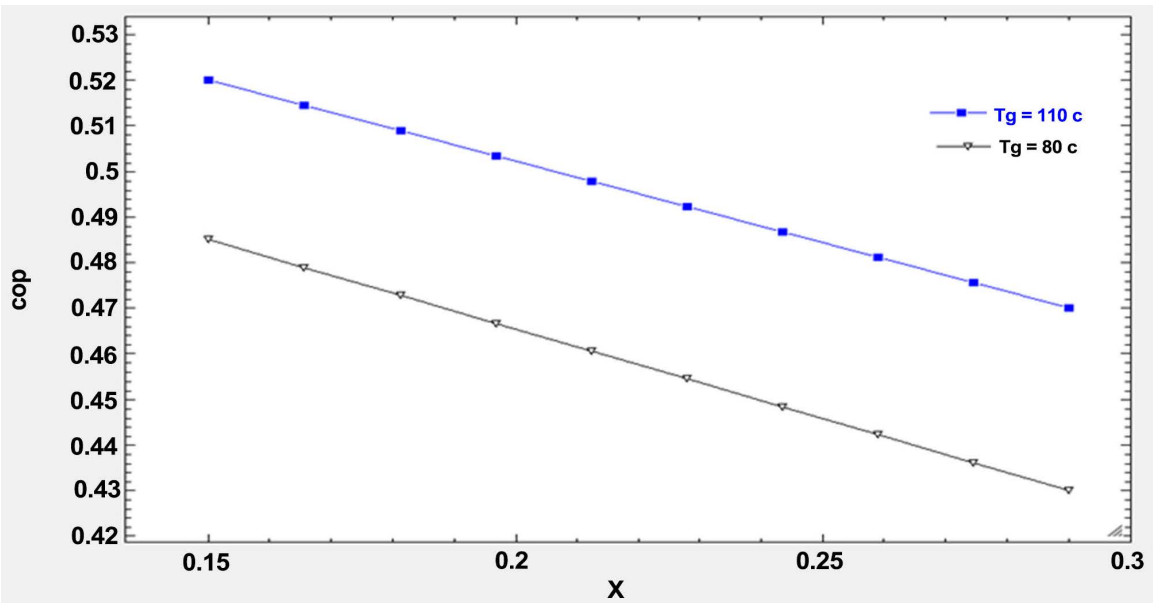

Figure 7. Effects of concentration ratios on the thermal performance coefficient at the two generation levels.
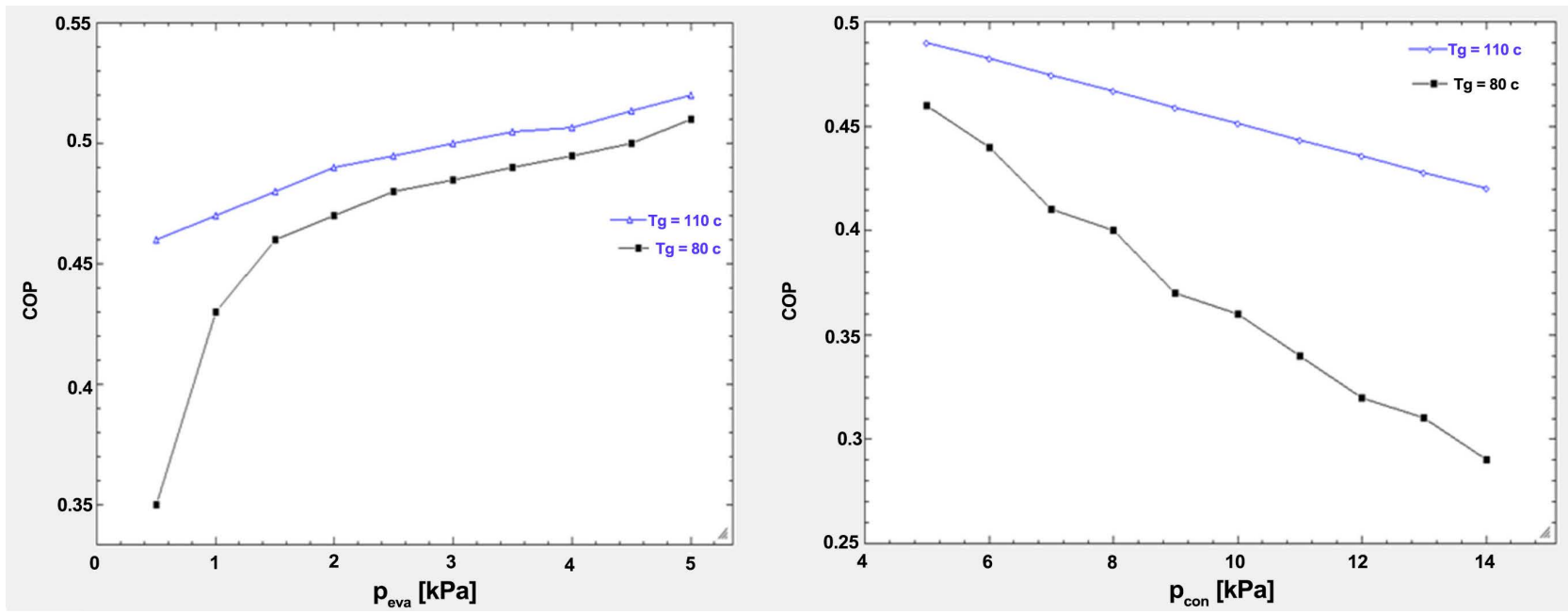

Figure 8. Evaporative pressure and condensation change with coefficient of thermal performance.

performance coefficient improved because when the condensation pressure increased, the pressure within the adsorption vessel increased. Any increase of the time required for the generation process to occur will result in a reduction of the condensate. Also, it was noticed from the same figure a reverse situation results with the increasing of the vaporization pressure. This indicates that the average flow rate of the cooling medium will increase with an increase of the coefficient of performance.

\subsection{Solar Performance Factor of the System}

The effect of the generation temperature on the solar coefficient associated with the radiation intensity and the area of the polarization and expressed by the solar thermal energy are shown in Figure 9.

\subsection{Effect of Solar Radiation Intensity}

This factor has a significant impact on the design of the system because its value 


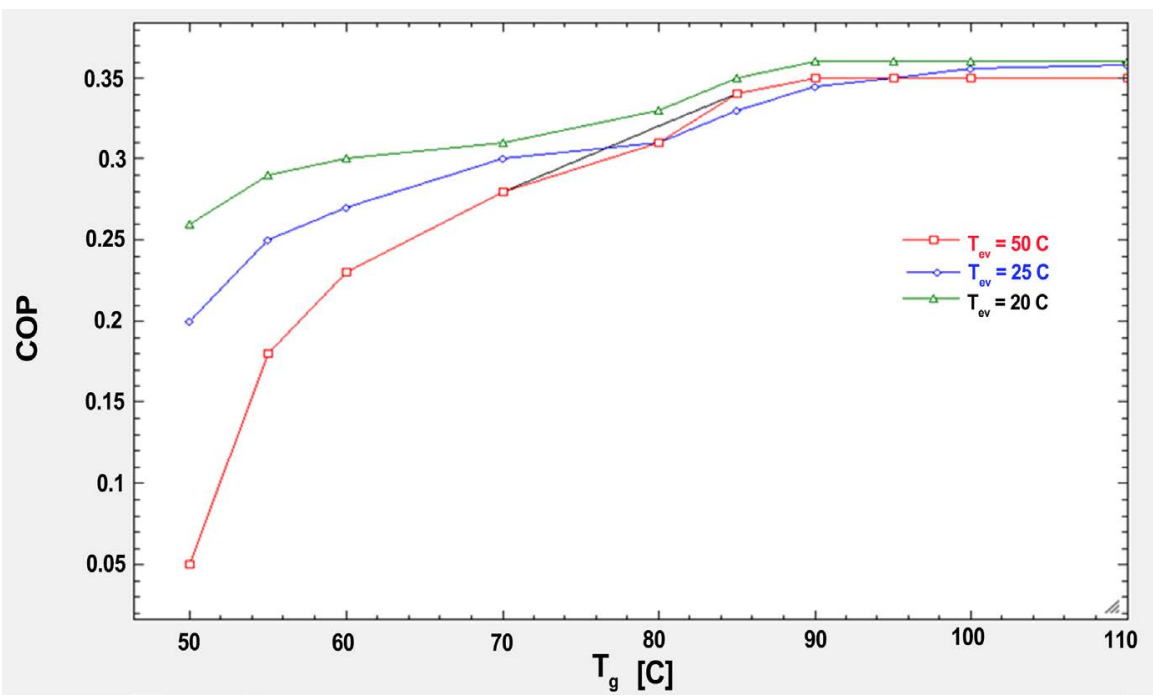

Figure 9. Solar performance coefficient schemes with generation and evaporation temperature.

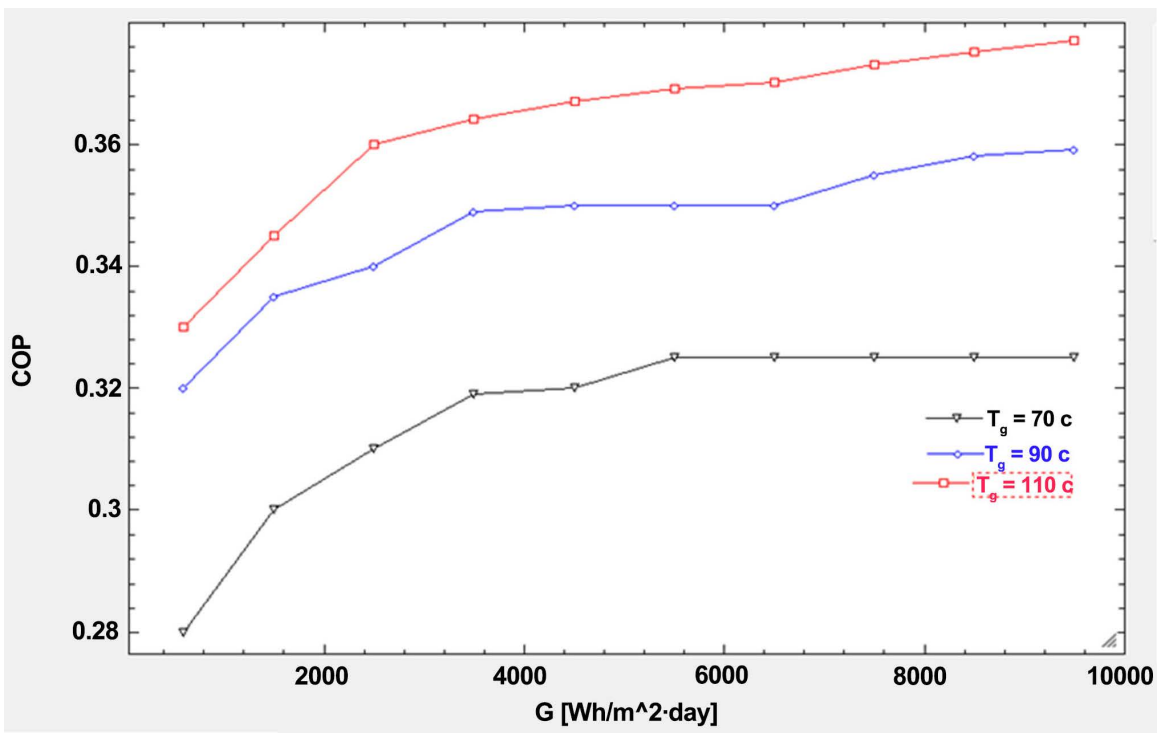

Figure 10. Changes in the solar performance coefficient with the intensity of solar radiation.

Table 6. Acquisition cost.

\begin{tabular}{ccc}
\hline System & \multicolumn{2}{c}{ Acquisition cost } \\
\hline PTCs & 35,000 & $€ / \mathrm{m}^{2}$ \\
Adsorption cooling & 125,000 & $€ / \mathrm{Kw}$ \\
\hline
\end{tabular}

will determine the amount of heat required, providing the required load for cooling. Figure 10 shows that changes in the monthly solar radiation values with the solar performance coefficient. With the increase in solar radiation an increase in the coefficient of solar performance was noticed to settle at a steady state value. 


\section{Economic Analysis}

For the economic analysis, it was considered that the system lifetime was 25 years. The analysis was carried out at constant pricing (without considering the rate of inflation) with a nominal discount rate of $3 \%$. The costs associated with the maintenance of the system were not considered, and it was considered that an annual cost of $€ 2.692$ was needed for the backup energy fossil fuels. The prices mentioned in Table 6 refer to PTCs and to the adsorption system that were obtained directly from the manufacturer [15].

\section{Conclusions}

Through the analytical and thermal analysis and the design of the system, the results of this research can be summarized as follows:

1) A new cooling system was designed for the adsorption system between two materials that were used to generate a medium and solar thermal energy was used to operate the system.

2) The possibility of working at a low generation temperature and a pressure of $70^{\circ} \mathrm{C}-80^{\circ} \mathrm{C}, 4-8 \mathrm{kpa}$, respectively, with a coefficient of performance $(\mathrm{COP}=$ $0.4-0.8$ ) during the summer months in the coastal zone, were reasonable.

3) The possibility of applying a system of air conditioners that operate with a small capacity and space with fixed and continuous loads, such as in steering or control rooms, and with engines used with heavy electric winches.

4) It was determined from the analysis that the system can function effectually and continuously without interruption during daytime and night.

\section{Conflicts of Interest}

The authors declare no conflicts of interest regarding the publication of this paper.

\section{References}

[1] Kaygusuz, K. (2011) Prospect of Concentrating Solar Power in Turkey: The Sustainable Future. Renewable and Sustainable Energy Reviews, 15, 808-814. https://doi.org/10.1016/j.rser.2010.09.042

[2] Solair, Increasing the Market Implementation of Solar Air-Conditioning Systems for Small and Medium Applications in Residential and Commercial Buildings. http://www.solair-project.eu

[3] Blair, N., Dobos, A., Freeman, J., Neises, T., Wagner, M., et al. (2014) System Advisor Model, SAM 2014.1.14: General Description. National Renewable Energy Laboratory (NREL), Golden, CO. https://doi.org/10.2172/1126294

[4] Bernardo, H., et al. (2009) Solutions to Improve Building Energy Classification in Portugal. 2009 2nd International Youth Conference on Energetics.

[5] GECOL (2010) GECOL Annual Report 2010. General Electricity Company of Tripoli, Libya.

[6] Li, M., Sun, C.J., Wang, R.Z. and Cai, W.D. (2004) Development of No Valve Solar Ice Maker. Thermal Engineering, 24, 865-872. 
https://doi.org/10.1016/j.applthermaleng.2003.10.002

[7] Elmnifi, M. and Imrayed, O. (2018) Use of Solar Energy for Building Air Conditioning and Domestic Hot Water Production-Case Study Elbrega-Libya.

[8] Wess, W. and Rommel, M. (2008) Process Heat Collectors, State of the Art within Task 33/IV.

[9] Saha, B.B., Akisawa, A. and Kashiwagi, T. (2001) Solar/Waste Heat Driven Two Stage Adsorption Chiller. Renewable Energy, 23, 93-101.

https://doi.org/10.1016/S0960-1481(00)00107-5

[10] NASA. NASA Prediction of Worldwide Energy Resources. https://power.larc.nasa.gov/

[11] EES Is a General Equation Solver that Can Solve Thousands of Coupled Non-Linear Algebraic and Differential Equations. EES Includes a Library of Thermodynamic and Transport Properties for Hundreds of Substances. http://www.fchart.com

[12] Askalanya, A.A., Ismail, M., Salema, I.M., Ali, A.H.H. and Morsyb, M.G. (2012) A Review on Adsorption Cooling Systems with Adsorbent Carbon. Renewable and Sustainable Energy Reviews, 16, 493-500. https://doi.org/10.1016/j.rser.2011.08.013

[13] Alghoul, M.A., Sopian, K., Sulaiman, M.Y., Azmi, B.Z. and Wahab, M.A. (2007) Review of Materials for Adsorption Refrigeration Technology. Anti-Corrosion Methods and Materials, 54, 225-229. https://doi.org/10.1108/00035590710762366

[14] El Fadar, A., Mimet, A. and Pérez-García, M. (2009) Modeling and Performance Study of a Continuous Adsorption Refrigeration System Driven by Parabolic trough Solar Collector. Solar Energy, 83, 850-861.

https://doi.org/10.1016/j.solener.2008.12.003

[15] Quintal, E.S., Bernardo, H.S., Amaral, P.G. and Neves, L.P. (2011) Use of Parabolic Trough Solar Collectors for Building Air Conditioning and Domestic Hot Water Production-Case Study. 3rd International Youth Conference on Energetics, Leiria, Portugal, 7-9 July 2011, 1-5. 